Journal of Physical Science, Vol. 28(1), 27-47, 2017

\title{
Synthesis, Crystal Structure and Vibrational Spectral Analysis of Guanidinium Hydrogen L-aspartate Single Crystal
}

\author{
Uma Devi Thangaraj, ${ }^{1 *}$ Meenakshi Rajagantham, ${ }^{2}$ Kalpana Govindarajulu ${ }^{3}$ \\ and Josephine Prabha Arulsamy ${ }^{4}$ \\ ${ }^{1}$ Department of Physics, Government Arts College for Women (Autonomous), \\ Pudukkottai, 622001, India \\ ${ }^{2}$ Department of Physics, Cauvery College for Women, Trichy, \\ Tamil Nadu, 620018, India \\ ${ }^{3}$ Department of Physics, K. Ramakrishnan College of Engineering, \\ Kariyamanikam Road, Trichy, 621112, India \\ ${ }^{4}$ Department of Physics, Bishop Heber College (Autonomous), \\ Trichy, 620017, India
}

*Corresponding author: kavin_shri@yahoo.co.in

Published online: 15 April 2017

To cite this article: Thangaraj, U. D. et al. (2017). Synthesis, crystal structure and vibrational spectral analysis of guanidinium hydrogen L-aspartate single crystal. J. Phys. Sci., 28(1), 27-47, https://doi.org/10.21315/jps2017.28.1.3

To link to this article: https://doi.org/10.21315/jps2017.28.1.3

\begin{abstract}
Single crystals of guanidinium hydrogen L-aspartate (GULAS), a salt of guanidine derivative, have been grown by slow-cooling method and characterised by infrared (IR) spectroscopy, powder and single-crystal x-ray powder diffraction (XRD). From the vibrational spectral analysis, the spectral band assignment is carried out to identify the various functional groups in GULAS. After arriving at the equilibrium geometry, the analysis of intramolecular charge transfer interactions using natural bond orbital (NBO) method, first order hyperpolarisability, molecular electrostatic potential and frontier molecular orbitals have been carried out using density functional theory. The second-order NLO response is also studied using Kurtz and Perry powder method.
\end{abstract}

Keywords: Single crystal, slow cooling method, XRD, FTIR, guanidinium hydrogen

\section{INTRODUCTION}

Second harmonic generation (SHG) is one of the most interesting phenomena observed in non-centrosymmetric crystals and is widely utilised for optical 
frequency conversion and modulation. Crystals of all amino acids except glycine, owing to the presence of chiral carbon atom and non-centrosymmetry, serve as candidate for non-linear optical (NLO) materials, ${ }^{1}$ widely used in SHG and ultimately in generating blue green lasers. ${ }^{2}$ Our recent research work is mostly centred around NLO materials, which are amino acid derivatives obtained from glycine, L-proline, etc. ${ }^{3,4}$ In addition to the ease of growing by slow evaporation solution technique (SEST), the characteristics of amino acid crystals can be modified using molecular engineering and chemical synthesis. ${ }^{5}$

Guanidines are the imido derivatives of urea, with one imine and two amine units. Guanidine derivatives are versatile intermediates used in the manufacture of plastics, resins, rubber chemicals, photo chemicals, fungicides and disinfectants in industries and many of their complexes are potential NLO materials. ${ }^{6-12}$ The solidstate complexation of guanidine with different organic acids such as aspartic acid, oxalic acid, etc. has an interesting aspect concerning the weak hydrogen bonds of $\mathrm{N}-\mathrm{H} . . . \mathrm{O}$ and $\mathrm{O}-\mathrm{H} . . . \mathrm{O} .{ }^{13-16}$

Guanidinium hydrogen L-aspartate (GULAS) is one which consists of guanidinium and aspartate ions, connected by strong $\mathrm{N}-\mathrm{H} \ldots \mathrm{O}$ hydrogen bonds. It crystallises in the orthorohmbic structure having four molecules per unit cell, with a noncentrosymmetric space group $P 2_{1} 2_{1} 2_{1}$. Though Krumbe and Haussühl have reported the detailed structural and physical properties of GULAS, the spectral analysis has not been reported in open literature. ${ }^{17} \mathrm{Hence}$, in the present study, an attempt is made to grow and characterise GULAS using Fourier-transform infrared (FTIR) spectroscopy. In order to support the experimental outcomes, the detailed vibrational spectral investigations using the scaled quantum mechanical (SQM) force field technique based on density functional theory (DFT) calculations is performed. Additionally, from the natural bond orbital analysis (NBO), electron charge transfer through intermolecular hydrogen bonding is explained.

\section{EXPERIMENTAL}

The stoichiometric portions of guanidinium carbonate and an aqueous solution of L-aspartic acid are made to react to synthesise GULAS. The reactants are thoroughly dissolved in double distilled water and stirred well, using a temperaturecontrolled magnetic stirrer to yield a homogeneous mixture of solution. Upon slow evaporation at room temperature, transparent crystalline salt of GULAS are obtained. Purification of the synthesised salt is done by repeated recrystallisation process. The chemical structure of GULAS is shown in Figure 1. 


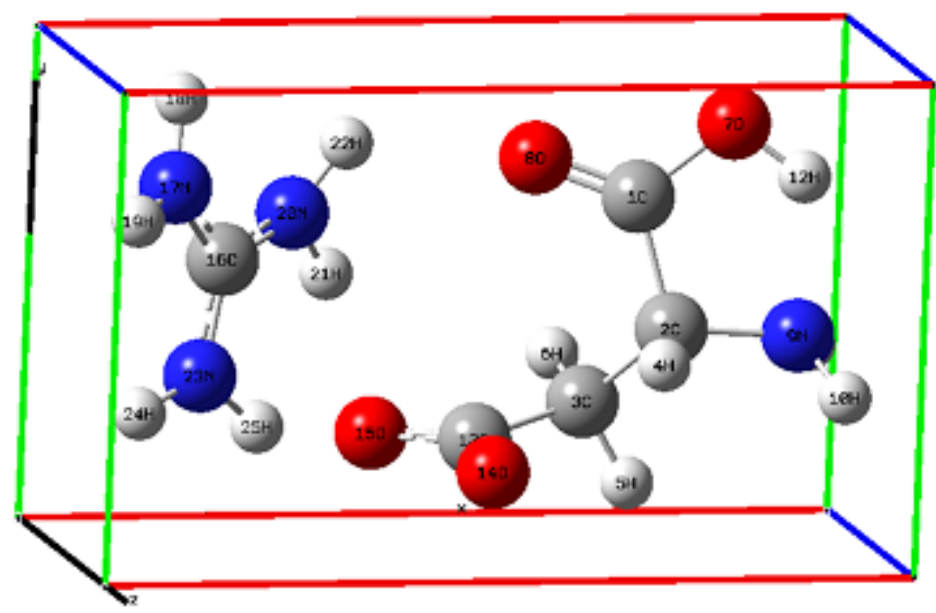

Figure1: Optimised structure of GULAS.

The reaction mechanism is as follows:

$$
\mathrm{C}_{2} \mathrm{H}_{7} \mathrm{~N}_{3} \mathrm{O}_{3}+\mathrm{C}_{4} \mathrm{H}_{7} \mathrm{NO}_{4} \rightarrow\left[\mathrm{CN}_{3} \mathrm{H}_{6}\right] \mathrm{C}_{4} \mathrm{H}_{6} \mathrm{NO}_{4}+\mathrm{H}_{2} \mathrm{O}_{+} \mathrm{CO}_{2}
$$

Saturated solution of GULAS is prepared at $35^{\circ} \mathrm{C}$ from recrystallised salt and filtered with microfilters. About $200 \mathrm{ml}$ of this solution is taken in a beaker and placed in a constant temperature bath having a temperature accuracy of $\pm 0.01^{\circ} \mathrm{C}$. Single crystal of GULAS is grown by the slow cooling method by reducing the temperature from $35^{\circ} \mathrm{C}$ at the rate of $0.1^{\circ} \mathrm{C}$ per day. Well-developed crystals of size $15 \times 5 \times 3 \mathrm{~mm}^{3}$ are harvested in a growth period of 15 days and one such is shown in Figure 2.

Structural analysis is carried out using powder and single crystal XRD (Enraf Nonius-CAD4) and the spectroscopic analysis using FTIR. All DFT calculations are performed with the Gaussian 09 program. ${ }^{18}$ The geometries were fully optimised in the gas phase at DFT levels by B3LYP functions, which combine Becke's three-parameter exchange function (B3) with the correlation function of Lee, Yang and Parr (LYP). Upon optimisation, all of the complexes worked out to have non-imaginary frequency geometries. These theoretical findings confirmed that the optimised structure of GULAS correspond to real minima on the potential energy surface, thus ensuring stability. 


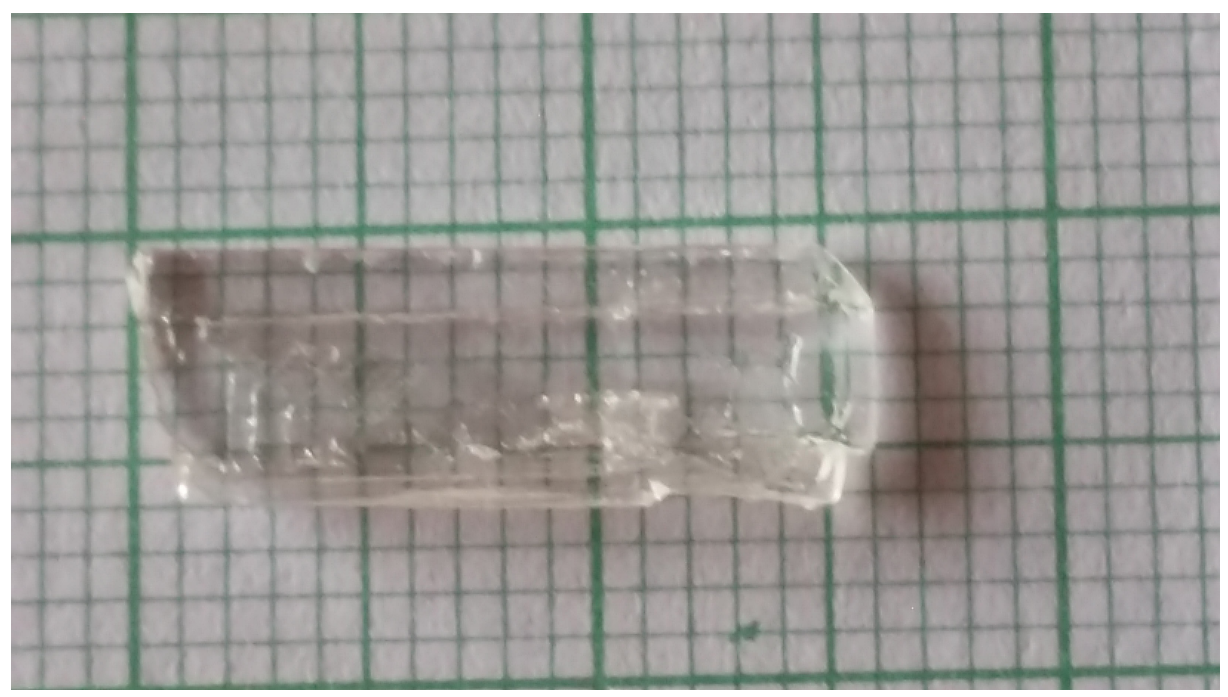

Figure 2: As-grown GULAS single crystal.

\section{STRUCTURAL ANALYSIS}

\subsection{X-ray Diffraction Studies}

The GULAS crystals are transparent and non-hygroscopic, with well-developed facial morphology (Figure 2). The single crystal XRD study shows that it crystallises in the orthorhombic crystal system with the lattice parameters as shown in Table 1.

Table 1: Orthorhombic lattice parameters of GULAS obtained from single crystal XRD.

\begin{tabular}{lllll}
\hline S. No. & $\mathrm{a}(\AA)$ & $\mathrm{b}(\AA)$ & $\mathrm{c}(\AA)$ & Reference \\
\hline 1. & 5.067 & 9.509 & 16.822 & Present Work \\
2. & 5.073 & 9.513 & 16.842 & 17 \\
\hline
\end{tabular}

The optimised geometrical parameters such as bond lengths and bond angles obtained at B3LYP/6-311G $(\mathrm{d}, \mathrm{p})$ level are given in Table 2. 
Table 2: Experimental and theoretical geometric data for GULAS at B3LYP/6-311G (d,p) level.

\begin{tabular}{llllll}
\hline Bond length $(\AA)$ & XRD & Bond angles $\left(^{\circ}\right)$ & & XRD \\
\hline \multicolumn{7}{l}{ Guanidinium ion ${ }^{19}$} & & & & \\
\hline C16-N17 & 1.3604 & 1.325 & N17-C16-N20 & 119.86 & 121.1 \\
C16-N20 & 1.3395 & 1.312 & N20-C16-N23 & 118.7039 & 118.8 \\
C16-N23 & 1.3336 & 1.330 & N17-C16-N23 & 121.4309 & 120 \\
N17-H18 & 1.0034 & 0.94 & & & \\
N17- H19 & 1.003 & 1.03 & & & \\
N20-H21 & 1.025 & 1 & & & \\
N20-H22 & 1.0093 & 1.09 & & & \\
N23-H24 & 1.004 & 0.85 & & 126.7 \\
N23-H25 & 1.0529 & 0.65 & & 114.4 \\
\hline L-aspartate ion ${ }^{18}$ & & & 112.7721 & \\
\hline C1-C2 & 1.5352 & 1.537 & C13-O14-015 & \\
C2-C3 & 1.5383 & 1.526 & C2-C3-C13 & 118.9 \\
C3-C13 & 1.5402 & 1.526 & C1-C2-C3 & 112.8789 & \\
C13-O14 & 1.263 & 1.252 & C1-C2-O7 & 118 & \\
C13-O15 & 1.3089 & 1.2572 & & & \\
C3-H5 & 1.0938 & 0.95 & & & \\
C3-H6 & 1.0889 & 1.02 & & & \\
C2-H4 & 1.095 & 0.95 & & & \\
C2-N9 & 1.486 & 1.492 & & & \\
N9-H10 & 1.0112 & 0.91 & & & \\
N9-H11 & 1.0139 & 0.94 & & & \\
\hline
\end{tabular}

The calculated theoretical values are in good agreement with the corresponding experimentally reported values. ${ }^{17,19}$ Powder X-Ray diffraction pattern of GULAS is given in Figure 3. 


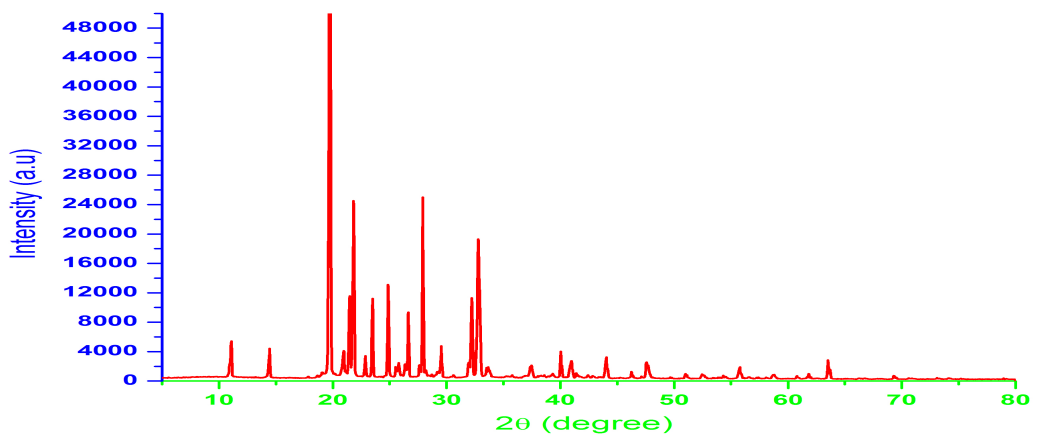

Figure 3: Powder x-ray diffraction pattern of GULAS.

\subsection{Vibrational Analysis}

Vibrational analysis of GULAS is made on the basis of aspartate and guanidinium groups. The recorded FTIR spectrum of GULAS is shown in Figure 4.

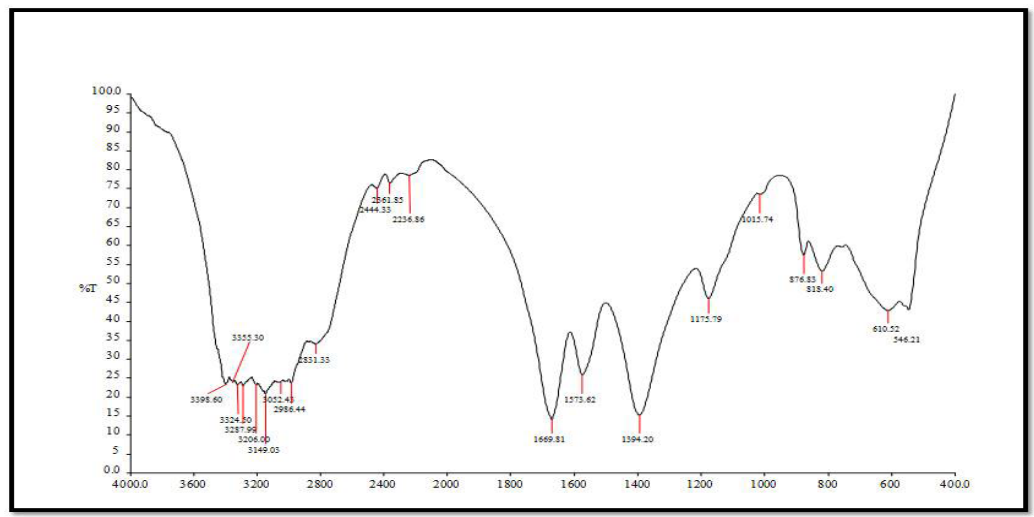

Figure 4: FTIR spectrum of GULAS.

The FTIR band observed at $3397 \mathrm{~cm}^{-1}$ is assigned as vibration due to $\mathrm{NH}_{2}$ asymmetric stretch of guanidine group. The in-plane $\mathrm{O}-\mathrm{H}$ deformation vibration usually appears as a strong band in the region 1440-1200 $\mathrm{cm}^{-1}$. The strong band at $1348 \mathrm{~cm}^{-1}$ in the IR spectrum corresponds to the vibrations due to C-O-H in-plane bending. As the carboxylic group vibrations due to the $\mathrm{C}=\mathrm{O}$ stretching are usually expected in the range $1725-1655 \mathrm{~cm}^{-1},{ }^{20,21}$ the band appearing at $1674 \mathrm{~cm}^{-1}$ for GULAS is assigned to the $\mathrm{C}=\mathrm{O}$ stretching vibrations. At 1007 and $892 \mathrm{~cm}^{-1}$, the 
vibrations respectively correspond to $\mathrm{CH}_{2 \text { scis }}$ and $\mathrm{CH}_{2 \text { rock. }}$. Few other in-plane and out of plane bending vibrations are assigned as shown in Table 3.

Table 3: Observed and calculated wave numbers $\left(\mathrm{cm}^{-1}\right)$ for GULAS at B3LYP/6-311G $(d, p)$ level.

\begin{tabular}{lcl}
\hline \multicolumn{2}{c}{ Wavenumber $\left(\mathrm{cm}^{-1}\right)$} & Assignments \\
\cline { 1 - 3 } FTIR & Calculated & \\
\hline 3397 & 3312 & $\mathrm{NH}_{2}$ asymmetric stretch \\
1674 & 1769 & $\mathrm{C}-\mathrm{H}$ stretching vibrations \\
1578 & 1572 & $\mathrm{C}=\mathrm{O}$ asymmetric stretch \\
1490 & 1425 & $\mathrm{C}-\mathrm{H}$ in plane bending vibration \\
1348 & 1394 & $\mathrm{O}-\mathrm{H}$ in plane deformation vibration \\
1301 & 1304 & $\mathrm{C}-\mathrm{N}-\mathrm{H}$ bending vibrations \\
1226 & 1229 & $\mathrm{C}-\mathrm{N}-\mathrm{H}$ bending vibrations \\
1156 & 1181 & $\mathrm{C}-\mathrm{N}-\mathrm{H}$ bending vibrations \\
1061 & 1051 & $\mathrm{CC}$ in- plane bending vibration \\
1007 & 1011 & $\mathrm{CC}$ in- plane bending vibration \\
892 & 894 & $\mathrm{CH}$ 2scis \\
844 & 850 & $\mathrm{CH}$ 2rock \\
823 & 804 & $\mathrm{C}-\mathrm{H}$ out of plane bending vibration \\
751 & 729 & $\mathrm{CC}$ out of plane bending vibration \\
619 & 639 & $\mathrm{CC}$ out of plane bending vibration \\
582 & 585 & $\mathrm{CC}$ out of plane bending vibration \\
532 & 539 & $\mathrm{CN}-$ out-of-plane bending modes \\
\hline
\end{tabular}

It is to be noted that the theoretically computed band values agrees well with the experimental result.

\subsection{Analysis of Fukui Indices}

The Fukui functions $(f(\mathrm{r}))$ are often used as indices to the local reactivity aiding to analyse the active atomic sites. The Fukui functions $(f(\mathrm{r}))$ measure the change in the electron density of an $\mathrm{N}$ electron system upon addition $\left(f^{+}(\mathrm{r})\right)$ or removal $(f(\mathrm{r}))$ of an electron. Atom condensed Fukui functions using the Mulliken population 
analysis (MPA) and the finite difference (FD) approximations approach introduced by Yang and Mortier ${ }^{22}$ were calculated using the equations:

$f_{k}^{n}=q_{k}(\mathrm{~N}+1)-q_{k}(\mathrm{~N})$ for nucleophilic attack

$f_{k}^{e}=q_{k}(\mathrm{~N})-q_{k}(\mathrm{~N}-1)$ for electrophilic attack and

$f_{k}^{r}=\frac{1}{2}\left(q_{k}(\mathrm{~N}+1)-q_{k}(\mathrm{~N}-1)\right)$ for radical attack

where $q_{k}(\mathrm{~N}+1), q_{k}(\mathrm{~N})$ and $q_{k}(\mathrm{~N}-1)$ are the electron densities of the $(\mathrm{N}+1)$, $N$ and $(\mathrm{N}-1)$ electron systems, respectively, and measure its electrophilic and nucleophilic tendencies respectively. The Fukui indices calculated for GULAS are listed in Table 4.

Table 4: Condensed Fukui functions for GULAS.

\begin{tabular}{lcccccc}
\hline Atom & $q_{k}(\mathrm{~N}+1)$ & $q_{k}(\mathrm{~N})$ & $q_{k}(\mathrm{~N}-1)$ & $f_{k}^{n}$ & $f_{k}^{e}$ & $f_{k}^{r}$ \\
\hline C 1 & 0.459903 & 0.604904 & 0.669064 & -0.145001 & -0.064160 & -0.104581 \\
C 2 & -0.207824 & -0.225117 & -0.218745 & 0.017293 & -0.006372 & 0.005460 \\
C 3 & -0.398827 & -0.439682 & -0.450314 & 0.040855 & 0.010632 & 0.025744 \\
H 4 & 0.138195 & 0.266375 & 0.273019 & -0.128180 & -0.006644 & -0.067412 \\
H 5 & 0.141355 & 0.201600 & 0.264566 & -0.060245 & -0.062966 & -0.061606 \\
H 6 & 0.154588 & 0.188184 & 0.232351 & -0.033596 & -0.044167 & -0.038882 \\
O 7 & -0.649075 & -0.543581 & -0.504698 & -0.105494 & -0.038883 & -0.072189 \\
O 8 & -0.658377 & -0.432675 & -0.470598 & -0.225702 & 0.037923 & -0.093890 \\
N 9 & -0.754045 & -0.787299 & -0.766058 & 0.033254 & -0.021241 & 0.016007 \\
H 10 & 0.293349 & 0.322035 & 0.350404 & -0.028686 & -0.028369 & -0.028528 \\
H 11 & 0.252554 & 0.312608 & 0.337172 & -0.060054 & -0.024564 & -0.042309 \\
H 12 & 0.333880 & 0.396555 & 0.422158 & -0.062675 & -0.025603 & -0.044139 \\
C 13 & 0.446871 & 0.483096 & 0.551720 & -0.036225 & -0.068624 & -0.052425 \\
O 14 & -0.517634 & -0.481659 & -0.238603 & -0.035975 & -0.243056 & -0.139516 \\
\hline
\end{tabular}


Table 4: (continued)

\begin{tabular}{lcccccc}
\hline Atom & $q_{k}(\mathrm{~N}+1)$ & $q_{k}(\mathrm{~N})$ & $q_{k}(\mathrm{~N}-1)$ & $f_{k}^{n}$ & $f_{k}^{e}$ & $f_{k}^{r}$ \\
\hline O 15 & -0.620100 & -0.622037 & -0.338633 & 0.001937 & -0.283404 & -0.140734 \\
C 16 & 0.818316 & 0.963463 & 1.047818 & -0.145147 & -0.084355 & -0.114751 \\
N 17 & -0.778347 & -0.810132 & -0.825022 & 0.031785 & 0.014890 & 0.048338 \\
H 18 & 0.350941 & 0.354811 & 0.372589 & -0.003870 & -0.017778 & -0.010824 \\
H 19 & 0.276992 & 0.345518 & 0.373069 & -0.068526 & -0.027551 & -0.048039 \\
N 20 & -0.733381 & -0.765063 & -0.812716 & 0.031682 & 0.047653 & 0.039668 \\
H 21 & 0.333420 & 0.375533 & 0.405838 & -0.042113 & -0.030305 & -0.036209 \\
H 22 & 0.347009 & 0.349684 & 0.361156 & -0.002675 & -0.011472 & -0.007073 \\
N 23 & -0.756823 & -0.783467 & -0.810675 & 0.026644 & 0.027208 & 0.026926 \\
H 24 & 0.288218 & 0.324401 & 0.364193 & -0.036183 & -0.039792 & -0.037988 \\
H 25 & 0.368842 & 0.401946 & 0.410944 & -0.033104 & -0.008998 & -0.021051 \\
\hline
\end{tabular}

The most susceptible sites for nucleophilic and electrophilic attacks are identified by these Fukui indices. The charge distributions point out that N20 is the preferred active site for reaction with nucleophilic species and $\mathrm{C} 3$ with electrophilic species. The pictorial representations of these indices are shown in Figure 5. 

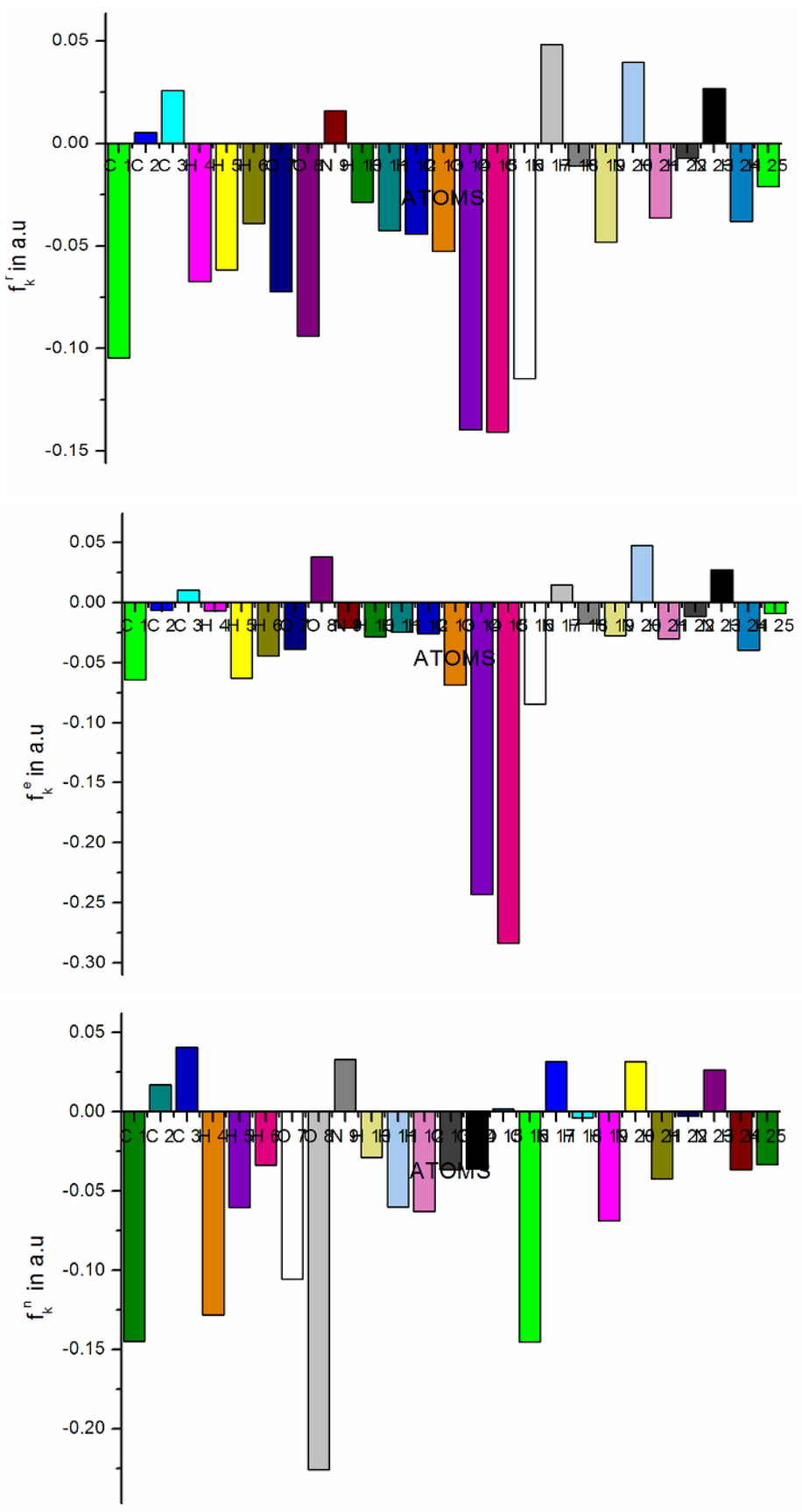

Figure 5: The pictorial representations of Fukui indices of GULAS. 


\subsection{HOMO-LUMO Analysis}

HOMO and LUMO are the main orbitals taking part in chemical reactions. The HOMO and LUMO energy characterises the ability of electron giving and electron accepting, respectively. The energy gap between HOMO and LUMO elucidates the kinetic stability, chemical reactivity, optical polarisability and chemical hardnesssoftness of a molecule. This is also utilised by the frontier electron density for prediction of the most reactive position in $\pi$-electron systems and also explains several types of reaction in conjugated systems. Surfaces for the frontier orbitals were drawn to recognise the bonding scheme of present compound. The positive phase is red and the negative one is green. The pictorial representations of the HOMO-LUMO of GULAS (in neutral, cationic and anionic geometries) are shown in Figure 6.

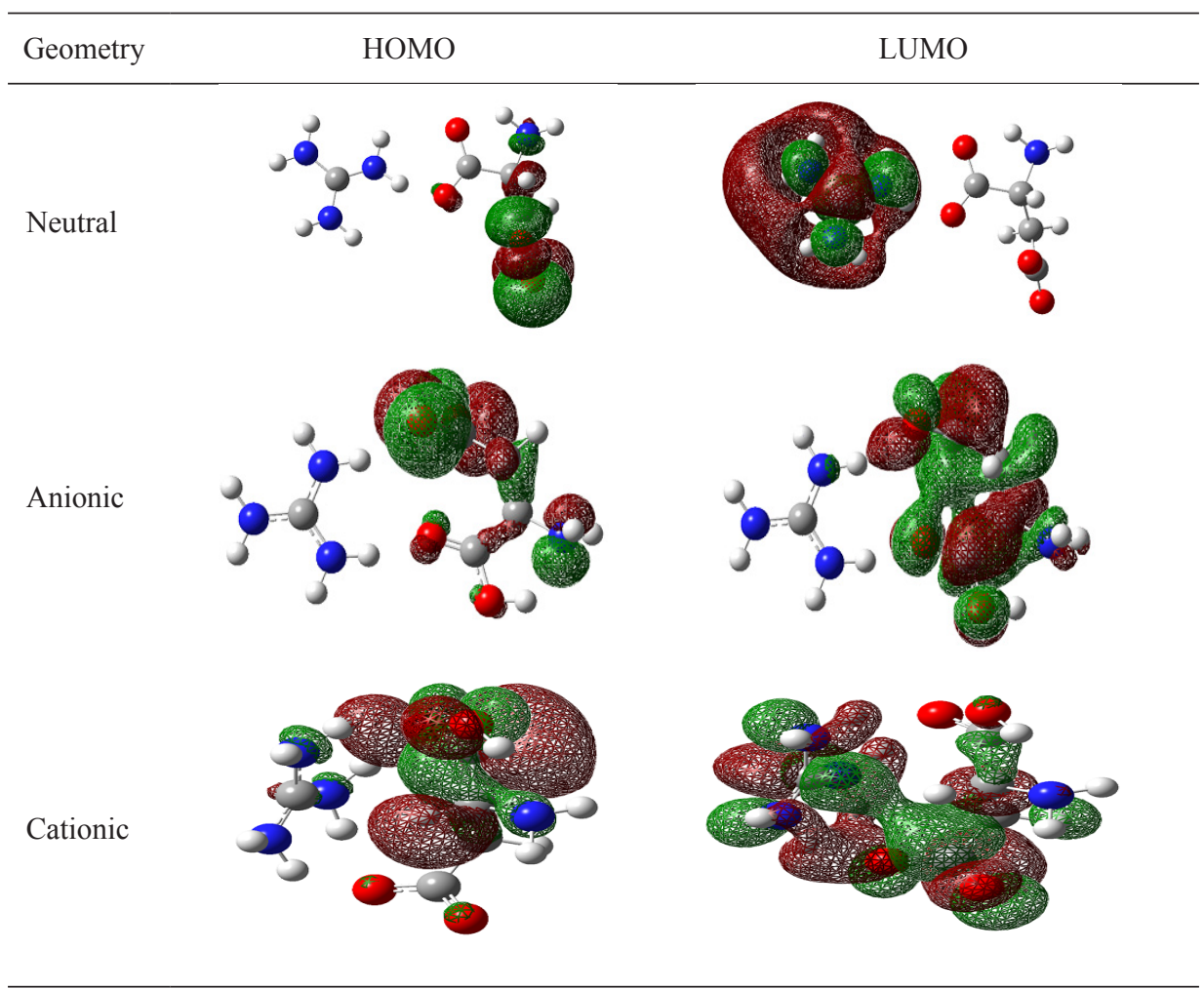

Figure 6: The pictorial representations of HOMO-LUMO of GULAS (in neutral, cationic and anionic geometries). 
HOMO is localised on the part of L-aspartate group, whereas LUMO is distributed over the entire guanidine group.

HOMO energy $=-8.9169 \mathrm{eV}$

LUMO energy $=-2.9088 \mathrm{eV}$

HOMO-LUMO gap $=6.0081 \mathrm{eV}$

Gauss-Sum 2.2 Program was used to calculate group contributions to the molecular orbitals (HOMO and LUMO) and prepare the density of states (DOS) spectrum in Figure 7.

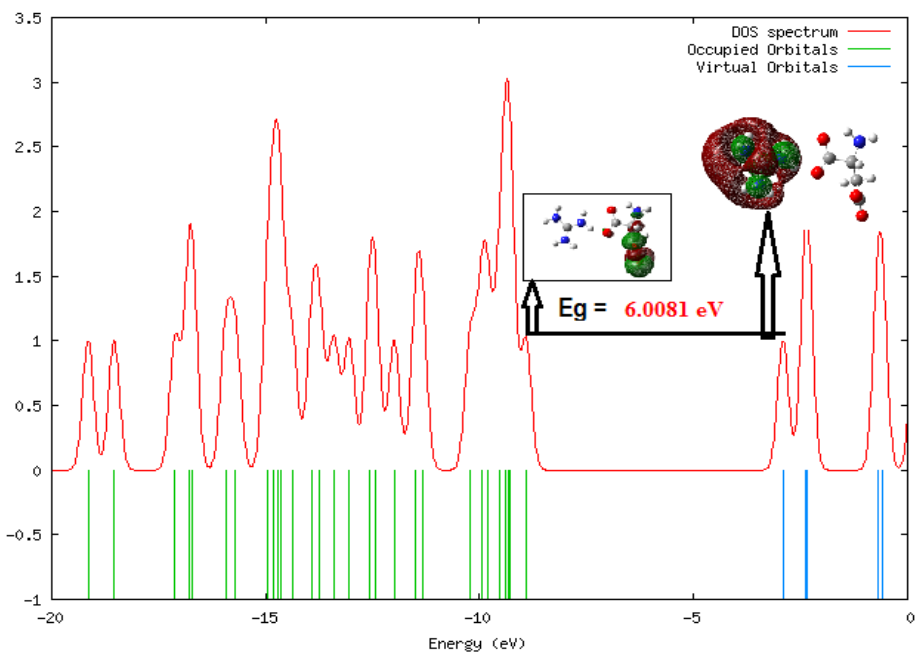

Figure 7: DOS spectrum of GULAS.

The DOS spectrum was formed by convoluting the molecular orbital information with GAUSSIAN curves of unit height. The green and blue lines in the DOS spectrum indicate the HOMO and LUMO levels, respectively. The DOS spectrum also supports the energy gap calculated by HOMO-LUMO analysis. The molecule having large and small energy gaps are referred as hard and soft molecule, respectively. The hard molecule is not more polarisable in comparison with the soft ones because they require immense energy for excitation. The calculated HOMOLUMO energies and energy gap for GULAS are listed in Table 5. 
Table 5: Global reactivity descriptors of GULAS under the applications of electric field.

\begin{tabular}{lcccc}
\hline \multirow{2}{*}{ Parameters } & \multicolumn{4}{c}{ Values } \\
\cline { 2 - 5 } & No field & Field $=0.0005$ a.u & Field $=0.001$ a.u & Field $=0.002$ a.u \\
\hline HOMO Energy & -8.9169 & -8.988 & -9.0378 & -8.8986 \\
LUMO Energy & -2.9088 & -2.9988 & -3.0384 & -3.1212 \\
Energy gap & 6.0081 & 5.9892 & 5.9994 & 5.7774 \\
Ionisation potential $(\mathrm{I})$ & 8.9169 & 8.988 & 9.0378 & 8.8986 \\
Electron affinity $(\mathrm{A})$ & 2.9088 & 2.9988 & 3.0384 & 3.1212 \\
Chemical hardness $(\eta)$ & 3.004 & 2.9946 & 2.9997 & 2.8887 \\
Chemical Potential $(\mu)$ & -5.9128 & -5.9934 & -6.0381 & -6.0099 \\
Softness (S) & 0.1664 & 0.1669 & 0.1666 & 0.1730 \\
Electrophilicity index $(\omega)$ & 5.8191 & 5.9976 & 6.0772 & 6.2517 \\
Nucleofugality $\left(\Delta \mathrm{E}_{\mathrm{n}}\right)$ & 8.7279 & 8.9965 & 9.1156 & 9.3729 \\
Electrofugality $\left(\Delta \mathrm{E}_{\mathrm{e}}\right)$ & 14.736 & 14.9857 & 15.1151 & 15.1504 \\
Charge Transfer $\left(\Delta \mathrm{N}_{\max }\right)$ & 1.9683 & 2.0014 & 2.0129 & 2.0804 \\
\hline
\end{tabular}

\subsection{Global Reactivity Descriptors under the Electric Field Influences}

Absolute hardness and softness are the important properties to measure the molecular stability and reactivity. It is apparent that the chemical hardness fundamentally signifies the resistance towards the deformation or polarisation of the electron cloud of the atoms, ions or molecules under small perturbation of the chemical reaction.

Using Koopman's theorem for closed-shell compounds, hardness ( $\eta$ ), softness (S) and the chemical potential $(\mu)$ can be defined as follows:

$$
\begin{aligned}
& \eta=\frac{I-A}{2} \\
& S=\frac{1}{2 \eta} \\
& \mu=\frac{-(I+A)}{2}
\end{aligned}
$$

where I and A are the ionisation potential and electron affinity of the compounds, respectively. Electron affinity refers to the capability of a ligand to accept precisely one electron from a donor. Ionisation energy is a fundamental descriptor of the chemical reactivity of atoms and molecules. High ionisation energy indicates high 
stability of chemical inertness and small ionisation energy indicates high reactivity of the atoms and molecules. Parr et al. have defined a new descriptor to quantify the global electrophilic power of the compound as electrophilicity index $(\omega)$, which defines a quantitative classification of the global electrophilic nature of a compound..$^{23} \omega$, referred as a measure of energy lowering due to maximal electron flow between donor and acceptor is defined as follows:

$$
\omega=\frac{\mu^{2}}{2 \eta}
$$

The significance of this new reactivity quantity has been recently demonstrated in understanding the toxicity of various pollutants in terms of their reactivity and site selectivity. The calculated value of electrophilicity index describes the biological activity of GULAS. All the calculated values of hardness, potential, and electrophilicity index are summarised in Table 5.

The maximum amount of the electronic charge that an electrophilic system may accept is given by the following equation:

$$
\Delta \mathrm{N}_{\max }=-\frac{\mu}{\eta}
$$

The maximum charge transfer $\Delta \mathrm{N}_{\max }$ in the direction of the electrophile is predicted using Equation 8 which describes the tendency of the molecule to acquire additional electronic charge from the environment. A similar effect as in the electrophilicity index is observed for maximum charge transfer. The charge transfer increases as the field increases (Table 5).

The two new reactivity indices to quantify the nucleophilic and electrophilic capabilities of leaving group are nucleofugality $\left(\Delta \mathrm{E}_{\mathrm{n}}\right)$ and electrofugality $\left(\Delta \mathrm{E}_{\mathrm{e}}\right)$ and they are defined as follows:

$$
\begin{aligned}
& \Delta \mathrm{E}_{\mathrm{n}}=\mathrm{EA}+\omega=\frac{(\mu+\eta)^{2}}{2 \eta} \\
& \Delta \mathrm{E}_{\mathrm{e}}=\mathrm{IP}+\omega=\frac{(\mu-\eta)^{2}}{2 \eta}
\end{aligned}
$$

All the calculated reactivity descriptors are presented in Table 5. 


\subsection{Molecular Electrostatic Potential (MESP) Analysis}

The molecular electrostatic potential, $V(r)$, at a given point $r(x, y, z)$ in the surrounding area of a molecule, is defined in terms of the interaction energy between the electrical charge generated from the electrons of molecule and a positive test charge (a proton) located at $r$. The molecular electrostatic potential (MESP) is related to the electronic density and is a very helpful descriptor in determining sites for electrophilic and nucleophilic attacks as well as hydrogen-bonding interactions. To predict reactive sites for electrophilic and nucleophilic attack for the title molecule, MEP was calculated at the B3LYP/6-311G optimised geometry. The negative (red) regions of MEP were related to electrophilic reactivity and the positive (blue) regions to nucleophilic reactivity as shown in Figure 8.

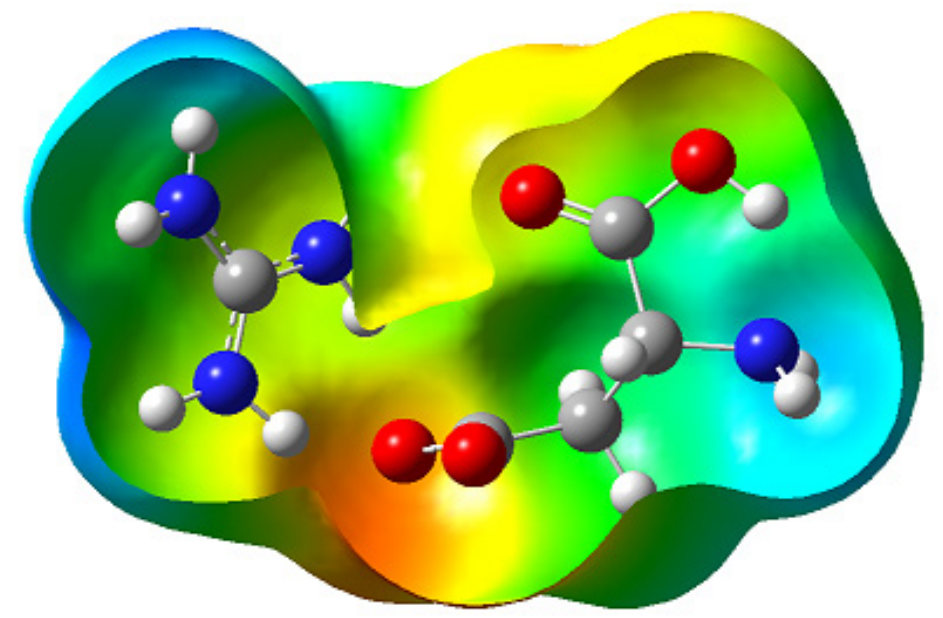

Figure 8: MESP surfaces of GULAS.

The negative electrostatic potential region is observed around the oxygen atoms of $\mathrm{CO}_{2}$ and carboxylic groups. A maximum positive region is localised on the carbon and hydrogen atoms indicating a possible site for nucleophilic attack.

\subsection{Electron Migration Analysis}

The NBO analysis is carried out by examining all possible interactions between "filled" (donor) Lewis-type NBOs and "empty" (acceptor) non-Lewis NBOs, and estimating their important stabilising energies by 2 nd order perturbation theory. Since these interactions lead to loss of occupancy from the localised NBOs of the idealised Lewis structure into the empty non-Lewis orbitals, they are referred to 
as delocalisation corrections to the zeroth-order natural Lewis structure. For each donor $\mathrm{NBO}(\mathrm{i})$ and acceptor $\mathrm{NBO}(\mathrm{j})$ with delocalisation $\mathrm{i} \rightarrow \mathrm{j} \mathrm{E}^{(2)}$ is estimated as:

$\mathrm{E}^{(2)}=\Delta \mathrm{E}_{\mathrm{ij}}=\mathrm{q}_{\mathrm{i}} \frac{\mathrm{F}(\mathrm{i}, \mathrm{j})^{2}}{\varepsilon_{\mathrm{j}}-\varepsilon_{\mathrm{i}}}$

where $\mathrm{q}_{\mathrm{i}}$ is the donor orbital occupancy $\varepsilon_{\mathrm{j}}$ and $\varepsilon_{\mathrm{i}}$ are diagonal elements orbital energies and $F(i, j)$ is the off diagonal NBO Fock matrix element. The larger $E^{(2)}$ value, the more intensive is the interaction between electron donors and acceptors, i.e., the more donation tendency from electron donors to electron acceptors and the greater the extent of conjugation of the whole system. DFT level computation is used to investigate the various second-order interactions between the filled orbitals of one subsystem and vacant orbitals of another subsystem, which is a measure of the delocalisation or hyper-conjugation.

Table 6: NBO analysis of second order perturbation theory of Fock matrix of GULAS at B3LYP/6-311G (d,p) level.

\begin{tabular}{llccc}
\hline Donor(i) & Acceptor $(\mathrm{j})$ & $\begin{array}{c}\mathrm{E}(2) \\
\mathrm{Kcal} / \mathrm{mol}\end{array}$ & $\begin{array}{c}\mathrm{E}(\mathrm{j})-\mathrm{E}(\mathrm{i}) \\
\text { a.u }\end{array}$ & $\begin{array}{c}\mathrm{F}(\mathrm{i}, \mathrm{j}) \\
\text { a.u }\end{array}$ \\
\hline $\mathrm{n}_{2}(\mathrm{O} 15)$ & $\sigma^{*}(\mathrm{C} 3-\mathrm{C} 13)$ & 13.69 & 0.65 & 0.085 \\
$\mathrm{n}_{2}(\mathrm{O} 15)$ & $\sigma^{*}(\mathrm{C} 13-\mathrm{O} 14)$ & 8.53 & 0.77 & 0.074 \\
$\mathrm{n}_{2}(\mathrm{O} 15)$ & $\sigma^{*}(\mathrm{C} 13-\mathrm{O} 14)$ & 3.81 & 0.34 & 0.034 \\
$\mathrm{n}_{3}(\mathrm{O} 15)$ & $\sigma^{*}(\mathrm{C} 13-\mathrm{O} 14)$ & 4.34 & 0.73 & 0.054 \\
$\mathrm{n}_{3}(\mathrm{O} 15)$ & $\pi^{*}(\mathrm{C} 13-\mathrm{O} 14)$ & 69.43 & 0.29 & 0.129 \\
$\mathrm{n}_{3}(\mathrm{O} 15)$ & $\sigma *(\mathrm{C} 13-\mathrm{O} 15)$ & 19.56 & 0.67 & 0.110 \\
$\mathrm{n}_{1}(\mathrm{~N} 17)$ & $\sigma^{*}(\mathrm{C} 16-\mathrm{N} 23)$ & 51.58 & 0.25 & 0.110 \\
$\mathrm{n}_{1}(\mathrm{~N} 20)$ & $\sigma^{*}(\mathrm{C} 16-\mathrm{N} 23)$ & 98.87 & 0.22 & 0.138 \\
$\mathrm{n}_{1}(\mathrm{~N} 20)$ & $\sigma *(\mathrm{~N} 20-\mathrm{H} 22)$ & 5.67 & 0.68 & 0.060 \\
\hline
\end{tabular}

As seen from Table 6, the strong interactions can be observed in guanidinium and aspartate moieties. In the guanidinium ion the lone pair $\mathrm{n}_{1}(\mathrm{~N} 20)$ presents the electron-transfer potentials of $98.87 \mathrm{kcal} / \mathrm{mol}$ to $\sigma^{*}(\mathrm{C} 16-\mathrm{N} 23)$. In aspartate moiety, the electrons of $n_{3}(\mathrm{O} 15)$ can be redistributed into $\pi^{*}(\mathrm{C} 13-\mathrm{O} 14)$ with the potential of $69.43 \mathrm{kcal} / \mathrm{mol}$. These two interactions stabilise the GULAS due to the highest stabilisation energies. 


\subsection{Thermodynamic Properties}

On the basis of vibrational analysis, the statistically thermodynamic functions such as heat capacity $\left(\mathrm{C}_{\mathrm{p}, \mathrm{m}}^{0}\right)$, entropy $\left(\mathrm{S}_{\mathrm{m}}^{0}\right)$, and enthalpy changes $\left(\mathrm{H}_{\mathrm{m}}^{0}\right)$ for GULAS were obtained from the theoretical harmonic frequencies and listed in Table 7.

Table 7: Thermo dynamical parameters of GULAS at B3LYP/6-311G $(\mathrm{d}, \mathrm{p})$ level.

\begin{tabular}{cccc}
\hline $\mathrm{T}(\mathrm{K})$ & $\mathrm{S}(\mathrm{J} / \mathrm{mol} . \mathrm{K})$ & $\mathrm{Cp}(\mathrm{J} / \mathrm{mol} . \mathrm{K})$ & $\Delta \mathrm{H}(\mathrm{kJ} / \mathrm{mol})$ \\
\hline 100.00 & 342.85 & 107.29 & 7.25 \\
200.00 & 436.11 & 169.00 & 21.06 \\
298.15 & 514.60 & 227.33 & 40.54 \\
300.00 & 516.01 & 228.39 & 40.96 \\
400.00 & 589.20 & 281.77 & 66.54 \\
500.00 & 657.08 & 326.78 & 97.04 \\
600.00 & 720.02 & 363.60 & 131.62 \\
700.00 & 778.41 & 393.77 & 169.53 \\
800.00 & 832.68 & 418.88 & 210.20 \\
900.00 & 883.27 & 440.09 & 253.18 \\
1000.00 & 930.61 & 458.24 & 298.12 \\
\hline
\end{tabular}

From this table, it can be observed that these thermodynamic functions are increasing with temperature ranging from 100 to $1000 \mathrm{~K}$ due to the fact that the molecular vibrational intensities increase with temperature and shown in Figure 9.

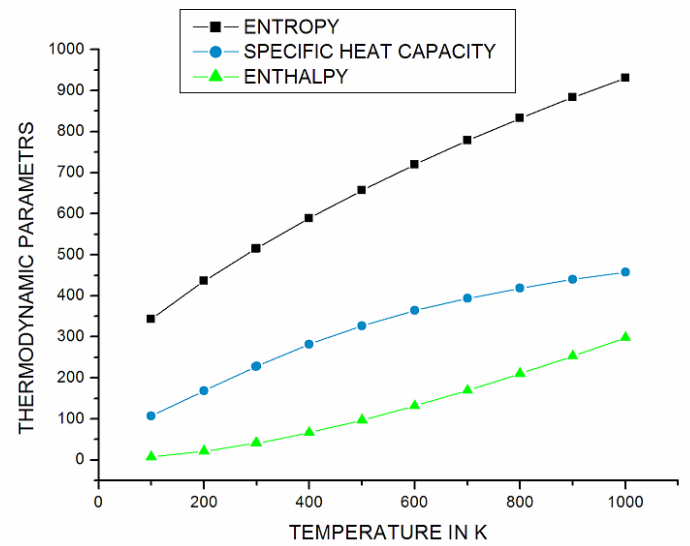

Figure 9: Thermodynamical parameters of GULAS. 


\subsection{Powder SHG Measurement}

The study of nonlinear optical conversion efficiency has been carried out using the modified experimental setup of Kurtz and Perry. ${ }^{24}$ A Q-switched Nd:YAG laser beam of wavelength $1,064 \mathrm{~nm}$, with an input power of $2.8 \mathrm{~mJ}$, and pulse width of $8 \mathrm{~ns}$ with a repetition rate of $10 \mathrm{~Hz}$ was used. The grown single crystal of GULAS was powdered with a uniform particle size and then packed in a microcapillary of uniform bore and exposed to laser radiations. The output from the sample was monochromated to collect the intensity of $532 \mathrm{~nm}$ component. The generation of the second harmonics was confirmed by the emission of green light. A sample of potassium dihydrogen phosphate (KDP), also powdered to the same particle size as the experimental sample, was used as a reference material in the present measurement. The SHG conversion efficiency of GULAS is found to be about 0.5 times that of KDP (Table 8).

Table 8: SHG signal energy output.

\begin{tabular}{ccc}
\hline $\begin{array}{c}\text { Input power } \\
\mathrm{mJ} / \text { pulse }\end{array}$ & $\begin{array}{c}\mathrm{KDP} \\
\mathrm{mV}\end{array}$ & $\begin{array}{c}\text { GULAS } \\
\mathrm{V}\end{array}$ \\
\hline 2.8 & 18 & 0.094 \\
\hline
\end{tabular}

This may be due to the molecular structure of GULAS in which the main bonds stem from hydrogen bridges between nitrogen atoms of the guanidinium group to oxygen atoms of aspartate group. The N. . . H . . O distances vary from 2.82 to $2.91 \AA$ with the aspartate. Further, there exists one N . . . H . . . O bond [2.91 $\AA]$ between the nitrogen atom of each aspartate ion and an oxygen atom of another aspartate ion are the reasons for the SHG efficiency possessed by this material.

\section{CONCLUSION}

Single crystal of GULAS has been grown. The optimised geometrical parameters were studied. Vibrational spectral analysis has been carried out using FTIR and DFT methods. The Fukui indices analysis points out that N20 is the preferred active site for reaction with nucleophilic species and C3 with electrophilic species through the analysis of Fukui indices. The theoretically calculated small HOMOLUMO gap explains the extent of intramolecular charge transfer interactions. From the calculated values of DFT based global reactivity descriptors the charge transfer increases under the influence of the electric field. The MESP analysis predicts that the negative regions are mainly localised on oxygen atoms of $\mathrm{CO}_{2}$ and carboxylic groups and maximum positive region is localised on the carbon 
and hydrogen atoms. NBO analysis confirms the presence of hydrogen bonding and investigates the stability as well as the intervening orbital interactions. The thermodynamic parameters are increasing with temperature ranging from 100 to $1000 \mathrm{~K}$. The second-order NLO response was evaluated with the Kurtz and Perry powder method to test its SHG efficiency.

\section{ACKNOWLEDGEMENTS}

One of the authors T. Uma Devi thanks University Grants Commission for the financial support under minor research project (grant no. MRP 5164/14(SERO/ UGC).

\section{REFERENCES}

1. Senthil, A. et al. (2009). Unidirectional growth of largest L-LMHCl dehydrate crystal by SR method. J. Cryst. Growth, 311, 544-547, https:// doi.org/10.1016/j.jcrysgro.2008.09.056.

2. Ramesh Kumar, G. et al. (2006). Influence of isoelectric $\mathrm{pH}$ on the growth linear and nonlinear optical and dielectric properties of i-threonine single crystals. Cryst. Growth Des., 6(6), 1308-1310, https://doi.org/10.1021/ cg050438g.

3. Uma Devi, T. et al. (2008). Growth and characterization of glycine picrate single crystal. Spectrochim. Acta A, 71, 340-343, https://doi.org/10.1016/j. saa.2007.12.048.

4. Uma Devi, T. et al. (2008). Growth and characterization of 1-prolinium picrate single crystal: A promising NLO crystal. J. Cryst. Growth, 310, 116123, https://doi.org/10.1016/j.jcrysgro.2007.10.011.

5. Uma Devi, T. et al. (2009). Synthesis, crystal growth and characterization of 1-proline lithium chloride monohydrate: A new semiorganic nonlinear optical material. Cryst. Growth Des., 9, 1370-1374, https://doi.org/10.1021/ $\operatorname{cg} 800589 \mathrm{~m}$.

6. Drozd, M. \& Dudzic, D. (2012). The guanidine and maleic acid (1:1) complex: The additional theoretical and experimental studies. Spectrochim. Acta A, 89, 243-251, https://doi.org/10.1016/j.saa.2011.12.069.

7. Drozd, M. \& Baran, J. (2006). Polarized vibrational studies of bisguanidinium hydrogenphosphate monohydrate. Spectrochim. Acta Part A, 64, 73-86, https://doi.org/10.1016/j.saa.2005.07.001. 
8. Drozd, M. (2006). The equilibrium structures, vibrational spectra, NLO and directional properties of transition dipole moments of diguanidinium arsenate monohydrate and diguanidinium phosphate monohydrate: The theoretical DFT calculations. Spectrochim. Acta A, 65, 1069-1086, https:// doi.org/10.1016/j.saa.2006.02.007.

9. Drozd, M., Dudzic, D. \& Pietraszko, A. (2013). Crystal structure, differential scanning calorimetric, infrared spectroscopy and theoretical studies of $\mathrm{C}\left(\mathrm{NH}_{2}\right)_{2}(\mathrm{NH})^{*} \mathrm{CH}_{2}=\mathrm{CHCOOH}$ noncentrosymmetric crystal. Spectrochim. Acta A Mol. Biomol. Spectrosc., 105, 135-148, https://doi.org/10.1016/j. saa.2012.12.013.

10. Russell, V. A., Etter, M. C. \& Ward, M. D. (1994). Guanidinium parasubstituted benzenesulfonates: Competitive hydrogen bonding in layered structures and the design of nonlinear optical materials. Chem. Mater., 6, 1206-1217, https://doi.org/10.1021/cm00044a019.

11. Arumanayagam, T. \& Murugakoothan, P. (2011). Studies on optical and mechanical properties of new organic NLO crystal: Guanidinium 4-aminobenzoate (GuAB). P. Mater. Lett., 65, 2748-2750, https://doi. org/10.1016/j.matlet.2011.05.081.

12. Sivashankar, V., Siddheswaran, R. \& Murugakoothan, P. (2011). Synthesis, growth, structural, optical and thermal properties of a new semiorganic nonlinear optical guanidinium perchlorate single crystal. Mater. Chem. Phys., 130, 323-326, https://doi.org/10.1016/j.matchemphys.2011.06.053.

13. Ekaterina, V. et al. (2006). Chiral three-dimensional microporous nickel aspartate with extended Ni-O-Ni bonding. J. Am. Chem. Soc., 128, 99579962, https://doi.org/10.1021/ja062743b.

14. Fleck, M., Emmerich, R. \& Bohatý, L. (2010). Crystal structure of caesium hydrogen $(L)$ - aspartate and an overview of crystalline compounds of aspartic acid with inorganic constituents. Cryst. Res. Tech., 45, 883-887, https://doi. org/10.1002/crat.201000129.

15. Zyss, J. et al. (1993). Synthesis and crystal structure of guanidinium 1-monohydrogentartrate: Encapsulation of an optically nonlinear octupolar cation. Acta Crystall., B49, 334-342, https://doi.org/10.1107/ S0108768192008395.

16. Anupama, G. \& Sanguramath, R. A. (2008). Three-dimensional hybrid networks based on aspartic acid. J. Chem. Sci., 120, 217-222, https://doi. org/10.1007/s12039-008-0025-0.

17. Krumbe, W. \& Haussühl, Z. (1987). Structure and physical properties of orthorhombic guanidinium phthalate $\left[\mathrm{CN}_{3} \mathrm{H}_{6}\right]_{2} \mathrm{C}_{8} \mathrm{H}_{4} \mathrm{O}_{4}$ and guanidinium hydrogen 1-aspartate $\left[\mathrm{CN}_{3} \mathrm{H}_{6}\right] \mathrm{C}_{4} \mathrm{H}_{6} \mathrm{NO}_{4}$. Kristallogr., 179, 267-279, https:// doi.org/10.1524/zkri.1987.179.1-4.267.

18. Frisch, M. J. et al. (2009). Gaussian 09W. Wallingford: Gaussian. 
19. Adams, J. M. (1978). The crystal structure of guanidinium hydrogen oxalate monohydrate. Acta Cryst., B34, 1218-1220, https://doi.org/10.1107/ s0567740878005245.

20. George, S. (2001). Infrared and Raman characteristic group wavenumbers, tables and charts. Chichester: Wiley.

21. Lin-Vien, D. et al. 1991. The hand book of infrared and Raman characteristic frequencies of organic molecules. New York: Academic Press.

22. Yang, W. \& Mortier, W. J. (1986). The use of global and local molecular parameters for the analysis of the gas-phase basicity of amines. J. Am. Chem. Soc., 108, 5708-5711, https://doi.org/10.1021/ja00279a008.

23. Parr, R. G., Szentpaly, L. V. \& Liu, S. J. (1999). Electrophilicity index. Am. Chem. Soc., 121, 1922-1924, https://doi.org/10.1021/ja983494x.

24. Kurtz, S. K. \& Perry, T. T. (1986). A powder technique for the evaluation of nonlinear optical materials. J. Appl. Phys., 39, 3798, https://doi. org/10.1063/1.1656857. 